\title{
Cerebral reticulum cell sarcoma after multiple renal transplants ${ }^{1}$
}

\author{
LESLIE B. BARNETT AND ELLIOTT SCHWARTZ \\ From the Department of Pathology, Stanford University School of Medicine, \\ Stanford, California, U.S.A.
}

SYNOPSIS A case is reported of a 34 year old white male with chronic renal failure secondary to glomerulonephritis who received four renal transplants over a period of five years. He died 25 months after the fourth transplant. Necropsy revealed a reticulum cell sarcoma-microglioma of the brain. The possibility that multiple transplants may have had a synergistic effect in the development of a malignant cerebral lymphoma in this patient is briefly discussed in the light of the current theories concerning the pathogenesis of the tumours in transplant recipients and in the context of the present therapeutic approach to graft rejection.

The high incidence of malignancies in patients who have undergone transplantation procedures is now well known (Penn, 1970; Schneck and Penn, 1971; Hoover and Fraumeni, 1973). The prognosis of patients receiving multiple transplants, however, has not been clearly established, although there is some preliminary evidence suggesting that the risk of cancer other than lymphoma is somewhat higher in these patients than in those receiving a single transplant (Hoover and Fraumeni, 1973). In a series of 37 tumours arising in renal homograft recipients, Penn (1970) briefly describes three cases of multiple transplants; the brain was not implicated in these patients. Schneck and Penn (1971) list one case of reticulum cell sarcoma involving the brain and cervical lymph nodes in a patient who received four kidney transplants. To our knowledge, no patients who received multiple transplants and subsequently developed a reticulum cell sarcoma limited to the brain have been reported in detail. The purpose of this paper is to describe such a case.

1 Supported by Graduate Neuropathology Training Grant 5T01 NS 05500-08, from the National Institute of Neurological Diseases and Stroke, and Grants CA-08122 and CA-05838 from the National Cancer Institute, U.S.P.H.S.

Reprint requests to Dr L. J. Rubinstein, Department of Pathology (Neuropathology), Stanford University School of Medicine, Stanford, California, 94305, U.S.A.

\section{CASE REPORT}

The patient was a 34 year old male who first came to medical attention because of an attack of acute glomerulonephritis at the age of 15 years. He had proteinuria and red and white cell casts in the urine, but his renal function studies were within normal limits and remained so for the next 10 years during multiple evaluations at the Stanford University Medical Center. Then, over the course of the subsequent year, he developed azotaemia, malignant hypertension, and ensuing chronic renal failure. $\mathrm{He}$ began to be maintained on haemodialysis at the age of 26 years; this was continued for three years until he received his first kidney transplant. The transplant was from a cadaver donor, functioned poorly for five weeks, and was rejected. Microscopic examination of the kidney showed acute rejection with infarction. Dialysis was resumed for another year until, at the age of 30 years, he received a second renal transplant from a living, related donor (his brother); it was rejected almost immediately, and microscopic examination confirmed a hyperacute rejection reaction with glomerular capillary fibrin thrombi. Haemodialysis was resumed until, at the age of 32 years, he received his third kidney transplant. This was from a living but non-related donor, and never functioned. Open biopsy revealed glomerular capillary thrombi with extensive cortical necrosis. The transplanted kidney was removed after a few days and a fourth transplant, from a cadaver donor, was inserted in its place. This kidney functioned adequately for 18 months but was then removed be- 


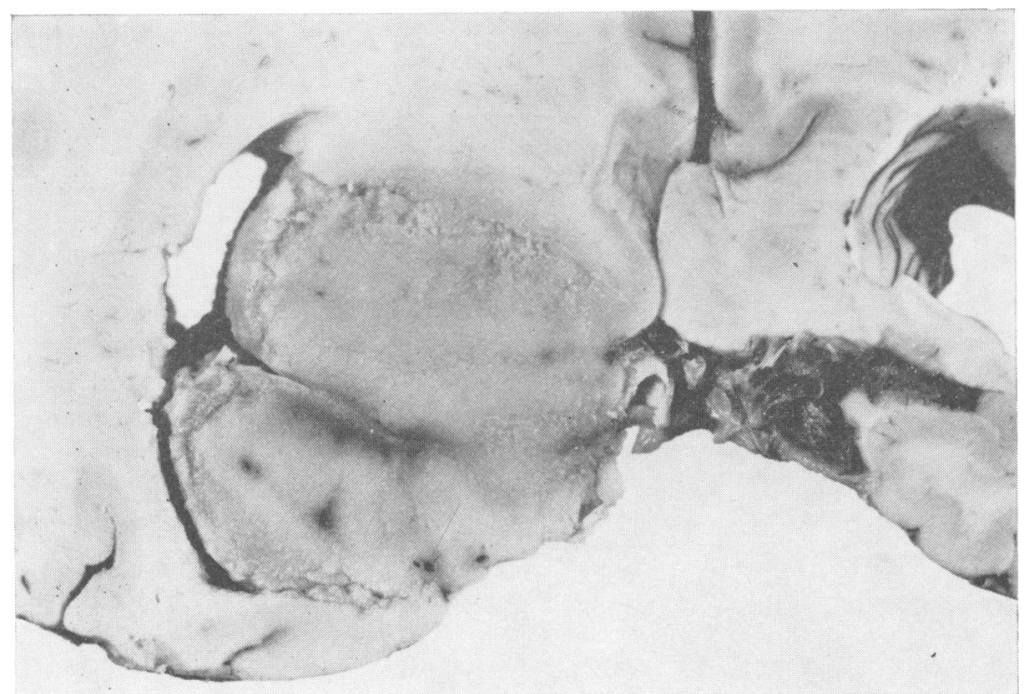

FIG. 1. Moderately welldemarcated grey homogeneous tumour in the medial portion of the left temporal lobe.

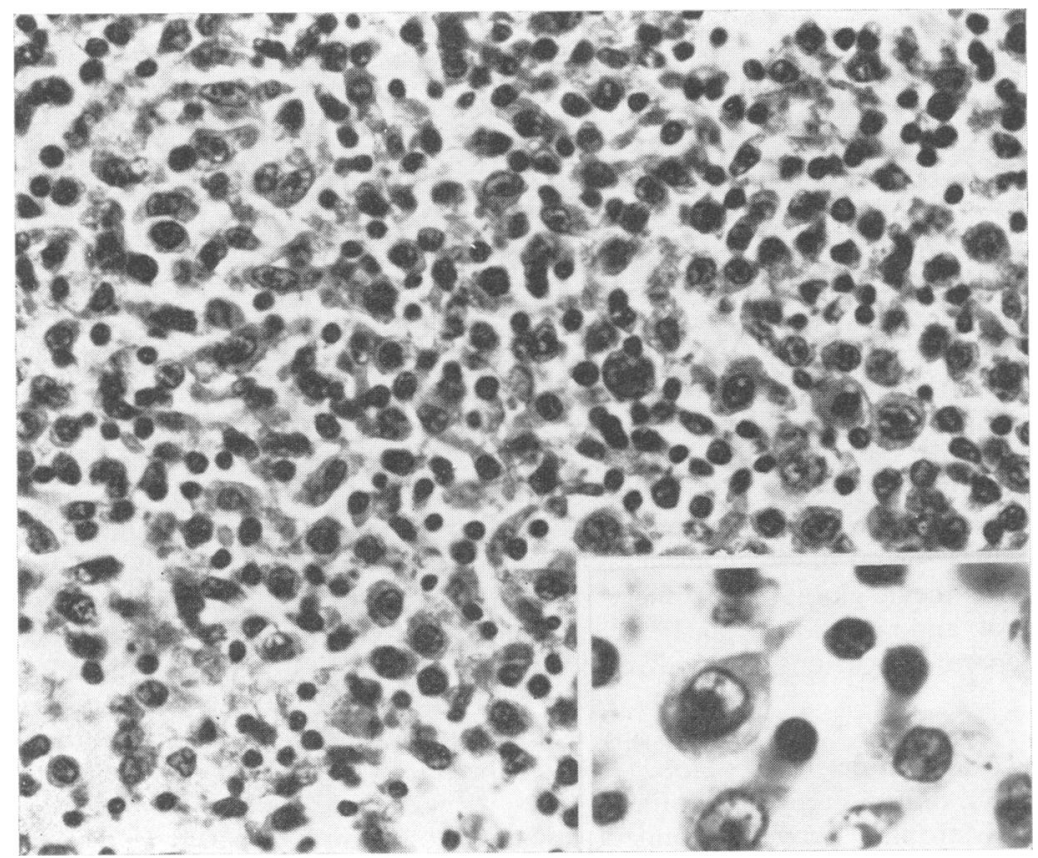

FIG. 2. Tumour composed of lymphocytes, histiocytes, and larger atypical cells of the reticuloendothelial system. The inset shows a characteristic malignant reticulum cell in the left centre field. $H$ and $E$, original magnification $\times 250$, inset $\times 1,200$.

cause of subacute rejection. All kidney transplants were performed at the University of California Medical Center, San Francisco. During this period he suffered multiple episodes of sepsis, pneumonia, and soft tissue infections; he also had cytomegalovirus and varicella-zoster infections. He lived for seven more months and during this time he entered
Stanford University Hospital on numerous occasions for arteriovenous shunt revisions of his haemodialysis. For the last three months, he suffered from recurrent headaches presumed to be due to the 'dysequilibrium syndrome' of haemodialysis. He last entered the hospital for a shunt revision, was acutely dialyzed and suffered a respiratory arrest 


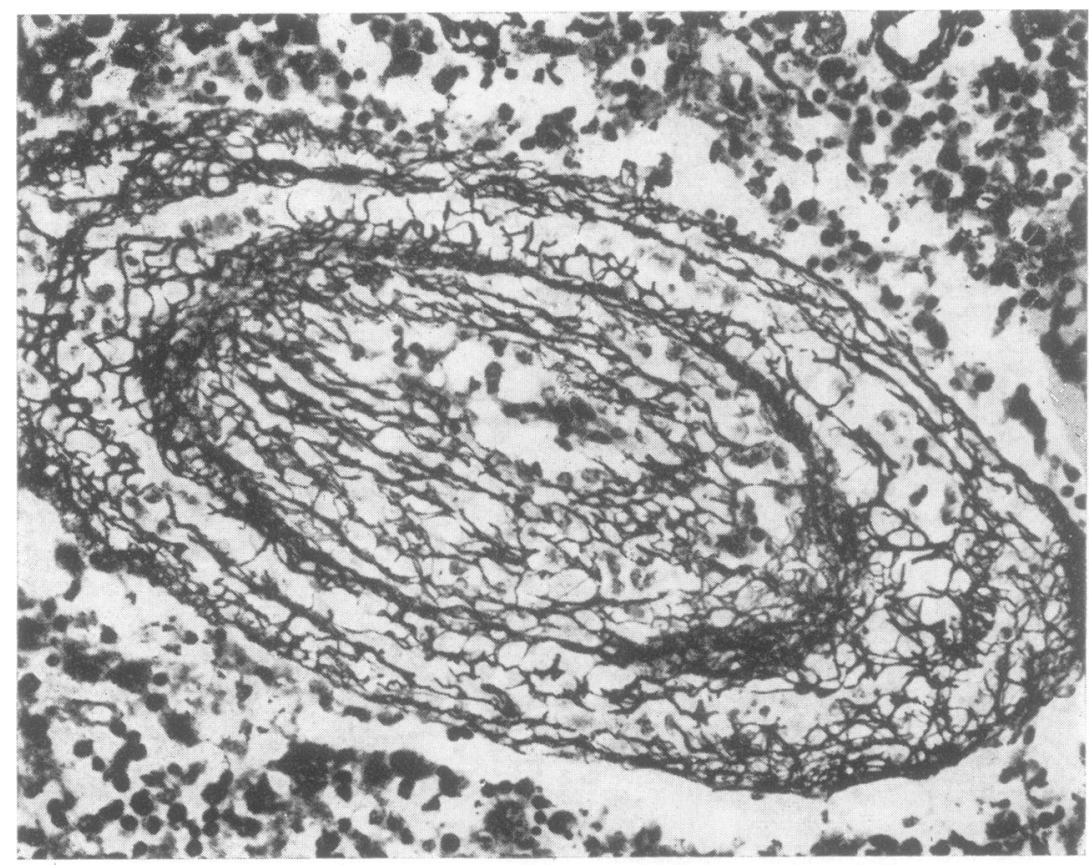

FIG. 3. Perivascular ringing of reticulin fibres, characteristic of reticulum-cell sarcomamicroglioma. GordonSweets' silver impregnation for reticulin, original magnification $\times 250$.

three hours later. He died after unsuccessful cardiopulmonary resuscitation, five years after the receipt of his fourth transplant. At no time during his long medical history did he have any neurological signs except for a left femoral nerve palsy secondary to one of the operative techniques.

His immunosuppressant therapy may be summarized as follows: azathioprine (Imuran), $50-150 \mathrm{mg}$ and prednisone, $15-100 \mathrm{mg}$ each four times daily, for 40 days after the first transplant, seven days after the second transplant, and for 18 months after the third and fourth transplants; actinomycin-D for 40 days after the first transplant; and antilymphocyte globulin, methyl prednisolone (SoluMedrol) and radiation $(2,000 r)$ to the kidney on two separate occasions after the fourth transplant.

NECROPSY The general necropsy examination revealed surgical absence of the kidneys, diffuse parathyroid hyperplasia, healing osteodystrophy, pericardial effusion, and a disseminated caseous granulomatous disease of unknown aetiology in the lungs and peripancreatic lymph nodes. In addition, lymph nodes from multiple sites showed absence of germinal centres and lymphocyte depletion in the paracortical areas. There was also focal hepatic necrosis and testicular atrophy.

Neuropathology The fixed brain weighed 1,650 g.
Examination of the external surface revealed diffuse enlargement of the left inferior temporal gyrus. On coronal section, a grey, finely granular tumour measuring up to $4 \times 4 \times 5 \mathrm{~cm}$ was found to occupy the left temporo-occipital cortex and white matter and to extend into the trigone (Fig. 1). Caudally it surrounded the occipital horn and occupied the calcarine cortex. It was sharply demarcated from the brain in places, but merged into the oedematous white matter in others.

The histological structure was that of a tumour of considerable cellular density and pleomorphism. Its periphery showed infiltration of the brain by neoplastic cells which were frequently arranged around blood vessels. Several types of tumour cells could be identified (Fig. 2): lymphocytes with hyperchromatic nuclei and scant cytoplasm; histiocytes with kidneyshaped, vesicular nuclei; and larger reticuloendothelial cells with distinct nuclear membranes, prominent nucleoli, abundant cytoplasm and clear nucleoplasm. Mitotic figures were occasionally seen. A silver impregnation for reticulin showed a characteristic ringing of reticulin fibres around blood vessels, with the entrapment of tumour cells in the reticulin meshwork (Fig. 3). Silver carbonate impregnations (Rio-Hortega and Weil-Davenport) were positive for microglia only at the periphery of the tumour. The microscopic appearance of this neoplasm, interpreted as a reticulum-cell sarcoma- 
microglioma of the brain (Rubinstein, 1972) is histologically similar to that of systemic histiocytic lymphoma according to the criteria of Rappaport (1966).

\section{DISCUSSION}

In their recent study based on 6,297 cases recorded in the Human Renal Transplant Registry of the American College of Surgeons, Hoover and Fraumeni (1973) report that the risk of a lymphoma developing after renal transplantation is 35 times greater than that seen in a population matched for age and sex. The excess is due almost entirely to the incidence of reticulum cell sarcoma, which was 350 times more common than expected. The following hypotheses have been proposed to explain the high incidence of neoplasms in transplant recipients: (1) chromosome breakage secondary to immunosuppressant drugs, especially azathioprine (Jensen, 1970); (2) continual antigenic stimulation of the homograft recipient (Walford, 1966; Armstrong et al., 1970); (3) proliferation of oncogenic viruses (Schwartz and AndréSchwartz, 1968); and (4) depression of the host's immunological surveillance apparatus (Dent et al., 1968; Hellström and Hellström, 1969).

The reticulum cell sarcomas and other lymphomas in transplant recipients are peculiar in having a marked tendency to implicate the central nervous system-50\% of the cases in Schneck and Penn's (1971) series, and 52\% in the series of Hoover and Fraumeni (1973). This contrasts with the relative infrequency with which the central nervous system is involved in patients who harbour visceral lymphoma and have not been transplant recipients. In 140 complete necropsies of patients with malignant lymphoma performed in this Department over a six year period, $15(11 \%)$ had histological confirmation of central nervous system involvement, predominantly leptomeningeal (Griffin et al., 1971). Furthermore, the series of Schneck and Penn showed that in eight of their 11 cases $(73 \%)$ the brain was, as in the present case, the only organ involved. It has been postulated that this is related to the poor ability of the central nervous system to mount an effective immunological reaction, as demonstrated in heterologous transplantation experiments (Greene, 1951). The brain lacks a lymphatic system, and it is possible that foreign antigenic material is cleared inadequately or remains in situ for longer periods than in more immunologically active areas of the body.

In our case, the patient's immunological system was depressed by a combination of chronic uraemia (Merrill, 1968), chemical immunosuppression (Leibowitz and Schwartz, 1971), recurrent viral infections (Starr and Berkovich, 1964; Schwartz and André-Schwartz, 1968), and multiple transplants with subsequent graft-vs-host reactions (Treiber and Lapp, 1973). The four transplants that he received gave him numerous prolonged exposures to the constant antigenic stimuli provided by each homograft and also to recurrent high doses of potent chemical immunosuppressants. If, as is believed, the foreign tissue graft provides a chronic impetus to lymphoid hyperplasia and subsequently to the development of lymphoma, then the multiple grafts may have had a synergistic effect in this regard, as suggested by Leibowitz and Schwartz (1971). Alternatively, it is possible that the earlier transplants may have played little or no role in the induction of his malignancy, since the average time lapse from receipt of the transplant to the subsequent development of an intracerebral lymphoma has been estimated at 16.5 months (Schneck and Penn, 1971), whereas this patient's tumour was discovered 25 months after his fourth transplant.

In many transplantation centres, it is now believed that the treatment for graft rejection is retransplantation rather than massive immunosuppression with its attendant risks of infection (Kountz, 1973). However, the role of multiple antigenic stimuli provided by successive grafts may have to be weighed against that of massive immunosuppression in the induction of subsequent malignancies. At this time, it is not possible to state which mode of therapy may carry the greater risk. The incidence and significance of lymphomas in patients receiving multiple transplants will need to be defined accurately in the future if this question is to be answered.

The authors thank Dr F. O. Belzer for his assistance in providing some of the medical records in this case, and Dr L. J. Rubinstein and Dr M. M. Herman for their valuable assistance in preparing the manu- 
script. The technical assistance of Miss̀ Carol Ineson is gratefully acknowledged.

\section{REFERENCES}

Armstrong, M. Y. K., Gleichmann, E., Gleichmann, H. Beldotti, L., André-Schwartz, J., and Schwartz, R. S. (1970). Chronic allogeneic disease. II. Development of lymphomas. Journal of Experimental Medicine, 132, 417439.

Dent, P. B., Peterson, R. D. A., and Good, R. A. (1968). The relationship between immunologic function and oncogenesis. In Immunologic Deficiency Diseases in Man. Birth Defects Original Article Series, 4, no. 1, 443-458.

Greene, H. S. N. (1951). The transplantation of tumors to the brains of heterologous species. Cancer Research, 11, 529-534.

Griffin, J. W., Thompson, R. W., Mitchinson, M. J., de Kiewiet, J. C., and Welland, F. H. (1971). Lymphomatous leptomeningitis. American Journal of Medicine, 51, 200-208.

Hellström, K. E., and Hellström, I. (1969). Cellular immunity against tumor antigens. Advances in Cancer Research, 12, 167-223.

Hoover, R., and Fraumeni, J. F., Jr (1973). Risk of cancer in renal-transplant recipients. Lancet, 2, 55-57.

Jensen, M. K. (1970). Effect of azathioprine on the chromosome complement of human bone marrow cells. International Journal of Cancer, 5, 147-151.

Kountz, S. L. (1973). The future of renal transplantation. Modern Medicine, 41, no. 16, 27-32.
Leibowitz, S., and Schwartz, R. S. (1971). Malignancy as a complication of immunosuppressive therapy. Advances in Internal Medicine, 17, 95-123.

Merrill, J. P. (1968). The immunologic capability of uremic patients. Cancer Research, 28, 1449-1451.

Penn, I. (1970). Malignant tumors in organ transplant recipients. In Results in Cancer Research. Vol. 35. Springer: Berlin.

Rappaport, H. (1966). Tumors of the Hematopoietic System. Atlas of Tumor Pathology, section 3, Fasc. 8. Armed Forces Institute of Pathology: Washington.

Rubinstein, L. J. (1972). Tumors of the Central Nervous System. Atlas of Tumor Pathology, 2nd series. Fasc. 6. Armed Forces Institute of Pathology: Washington.

Schneck, S. A., and Penn, I. (1971). De-novo brain tumours in renal-transplant recipients. Lancet, 1, 983-986.

Schwartz, R. S., and André-Schwartz, J. (1968). Malignant lymphoproliferative diseases: interactions between immunological abnormalities and oncogenic viruses. Annual Review of Medicine, 19, 269-282.

Starr, S., and Berkovich, S. (1964). Effects of measles, gammaglobulin-modified measles and vaccine measles on the tuberculin test. New England Journal of Medicine, 270, 386391.

Treiber, W., and Lapp, W. S. (1973). Graft-versus-hostinduced immunosuppression. The effect of antigenic stimulation on cell-mediated and humoral immune responses. Transplantation, 16, 211-216.

Walford, R. L. (1966). Increased incidence of lymphoma aftere injections of mice with cells differing at weak histocompatibility loci. Science :152, 78-80. 